\title{
Long term survival, health, social functioning, and education in patients with European Lyme neuroborreliosis: nationwide population based cohort study
}

\author{
Niels Obel, ${ }^{1}$ Ram B Dessau, ${ }^{2}$ Karen A Krogfelt, ${ }^{3}$ Jacob Bodilsen, ${ }^{4}$ Nanna S Andersen, ${ }^{5}$ \\ Jens K Møller, ${ }^{6}$ Casper Roed, ${ }^{1}$ Lars H Omland, ${ }^{1}$ Claus B Christiansen, ${ }^{7}$ Svend Ellermann-Eriksen, ${ }^{8}$ \\ Jette M Bangsborg, ${ }^{9}$ Klaus Hansen, ${ }^{10}$ Thomas L Benfield, ${ }^{11}$ Kenneth J Rothman, ${ }^{12,13}$ \\ Henrik T Sørensen, ${ }^{12}$ Christian $\varnothing$ Andersen, ${ }^{14}$ Anne-Mette Lebech ${ }^{1}$
}

For numbered affiliations see end of article.

Correspondence to: $\mathrm{N}$ Obel niels.obel@regionh.dk

Additional material is published online only. To view please visit the journal online.

Cite this as: $B M J$ 2018;361:k1998 http://dx.doi.org/10.1136/bmj.k1998

Accepted: 16 April 2018

\section{ABSTRACT}

OBJECTIVE

To estimate long term survival, health, and educational/social functioning in patients with Lyme neuroborreliosis compared with the general population.

\section{DESIGN}

Nationwide population based cohort study using national registers.

SETTING

Denmark.

\section{PARTICIPANTS}

All Danish residents diagnosed during 1986-2016 as having Lyme neuroborreliosis $(n=2067)$, defined as a positive Borrelia burgdorferi intrathecal antibody test and a clinical diagnosis of Lyme borreliosis, and a comparison cohort from the general population matched on sex and date of birth $(n=20670)$.

MAIN OUTCOME MEASURES

Mortality rate ratios, incidence rate ratios of comorbidities, and differences in educational and social outcomes.

RESULTS

Mortality among patients with Lyme neuroborreliosis was not higher than in the general population (mortality rate ratio $0.90,95 \%$ confidence interval 0.79 to 1.03 ). Lyme neuroborreliosis patients had increased risk of haematological (incidence rate ratio $3.07,2.03$ to 4.66 ) and non-melanoma skin cancers $(1.49,1.18$ to 1.88$)$. At diagnosis, Lyme neuroborreliosis patients had slightly higher employment and lower disability pension rates.

\section{WHAT IS ALREADY KNOWN ON THIS TOPIC}

In Europe, Lyme neuroborreliosis is among the most frequent bacterial infections of the nervous system, but the long term prognosis of the disease is poorly described

\section{WHAT THIS STUDY ADDS}

Lyme neuroborreliosis had no substantial effect on survival, health, and social parameters

Compared with members of the comparison cohort, patients had a threefold higher risk of haematological cancer, almost $50 \%$ higher risk of non-melanoma skin cancer, and a slightly higher risk of disability pension

Lyme neuroborreliosis patients have increased risk of haematological and non-melanoma skin cancers but can otherwise be assured that their long term prognosis is excellent

After five years, patients and comparison cohort members had similar numbers of hospital contacts (difference $-0.22,95 \%$ confidence interval -0.45 to 0.02 , in-hospital days/year; $0.37,-0.10$ to 0.83 , outpatient visits/year), employment rates (difference $1.5 \%,-2.1 \%$ to $5.1 \%$ ), income (difference $-1000,-20000$ to 18000 , Danish kroner), days of sick leave (difference $-0.3,-3.5$ to 3.0 , per year), rates of receipt of a disability pension (difference $-0.9 \%,-3.2 \%$ to $1.3 \%$ ), and number of children (difference $-0.10,-0.27$ to 0.08 ). More patients were married (difference $4.8 \%, 2.2 \%$ to $7.4 \%$ ) and had completed high school education (difference $7 \%$, $1 \%$ to $12 \%)$.

\section{CONCLUSION}

A verified diagnosis of Lyme neuroborreliosis had no substantial effect on long term survival, health, or educational/social functioning. Nevertheless, the diagnosis decreased labour market involvement marginally and was associated with increased risk of haematological and non-melanoma skin cancers.

\section{Introduction}

Lyme neuroborreliosis is a tickborne infection caused by the spirochetes of the Borrelia burgdorferi sensu lato complex (including $B$ garinii and $B$ afzelii in Europe). In Europe, Lyme neuroborreliosis is among the most frequent bacterial infections of the nervous system and mainly manifests as a self limiting, subacute, painful meningoradiculitis with concomitant lymphocytic cerebrospinal fluid inflammation. ${ }^{1-6}$ In children, Lyme neuroborreliosis primarily leads to subacute lymphocytic meningitis. $^{7}$

Antibiotic treatment improves neurological symptoms. However, studies on the long term outcome of Lyme neuroborreliosis are scarce and hampered by small study populations, short term follow-up, and lack of adequate comparison cohorts. ${ }^{3}$ 8-13 A systematic review of 44 clinical trials reported a $28 \%$ prevalence of residual symptoms after Lyme neuroborreliosis, including fatigue, pain, and neurological or cognitive sequelae. Few of the studies included control cohorts. ${ }^{14}$ Improved information on long term prognosis after an episode of Lyme neuroborreliosis is needed by patients, medical staff, and healthcare providers.

We used a nationwide population based matched cohort design to compare long term survival, health, 
social functioning, and education among patients with Lyme neuroborreliosis and a comparison cohort from the general population. To establish whether potential differences stemmed from family related factors, we also compared the same outcomes among family members of the patient and comparison cohorts.

\section{Methods}

Setting

Denmark's population on 31 December 2017 was 5.7 million people. Tax supported healthcare is provided free of charge to all Danish residents. Almost 5000 intrathecal antibody tests for $B$ burgdorferi are performed yearly in Denmark. ${ }^{2}$

\section{Data sources}

We used a population based nationwide cohort design, as described previously. ${ }^{15}$ We used the unique 10 digit personal identification number assigned to all Danish residents at birth or on immigration to track individuals in Danish national health and administrative registries. Data on $B$ burgdorferi intrathecal antibody tests came from data files obtained from all Danish microbiology laboratories that performed this test during the period 1 January 1985 to 1 March 2016. B burgdorferi specific intrathecal antibody production was measured by capture enzyme linked immunosorbent assays (see supplementary appendix). ${ }^{16}$ Additional data came from the Danish Civil Registration System, the Danish National Patient Registry (DNPR), the Danish Cancer Registry, the Employment Classification Module, the Personal Income Statistics database, and the Danish Educational Attainment Registry (see supplementary appendix).

\section{Study population}

Lyme neuroborreliosis patient cohort

We identified the Lyme neuroborreliosis patient cohort through collaboration with all microbiology laboratories in Denmark. Using electronic and paper laboratory files, we identified all people who had a $B$ burgdorferi intrathecal antibody test performed during the period 1 January 1985 to 1 March 2016. From this population, we extracted all patients with a positive $B$ burgdorferi intrathecal IgG and/or IgM test who were Danish residents at study inclusion (supplementary figure A). We defined the first date of a positive $B$ burgdorferi intrathecal antibody test as the date of study inclusion. We excluded patients from the study if they were not registered with a diagnosis of borreliosis in the DNPR within one year after study inclusion or had a contact with a department of neurology earlier than one year before study inclusion.

\section{Population comparison cohort}

For each Lyme neuroborreliosis patient, we used the Danish Civil Registration System and the DNPR to identify all Danish residents with the same sex and date of birth as the patient who had not tested positive for $B$ burgdorferi intrathecal antibodies and who met the study's inclusion and exclusion criteria (other than a diagnosis of borreliosis) described above for the patient cohort. From this population, we extracted 10 people at random for each patient. People in the population comparison cohort were assigned the same date of study inclusion as the Lyme neuroborreliosis patients to whom they were matched.

\section{Family member cohorts}

A diagnosis of Lyme neuroborreliosis may be related to healthcare seeking behaviour and outdoor recreational activities and thereby to higher socioeconomic status. To assess the magnitude of this effect, we used the Danish Civil Registration System to identify siblings and parents of the Lyme neuroborreliosis patients and of members of the population comparison cohort. Family members were assigned the same date of study inclusion as their relatives in the Lyme neuroborreliosis patient cohort or population comparison cohort (supplementary figure A). As registration of parents is complete only for people born after 1957, family members could not be identified for all study participants.

\section{Statistical analysis}

We ascertained time to death, diagnoses of cancers, and potential medical sequelae (supplementary appendix). We calculated time from date of study inclusion to 1 March 2016, death, emigration, loss to follow-up, or event of interest, whichever came first. We calculated mortality rate ratios and incidence rate ratios as measures of relative risk. We included patients registered with a diagnosis of borreliosis in the DNPR up to one year after study inclusion. As this may introduce immortal time bias, we did a sensitivity analyses in which we calculated time from the later of study inclusion and registration in the DNPR.

For each person in the patient and comparison cohorts, we ascertained the number of hospital inpatient days and outpatient hospital visits, employment status, personal income, number of days of sick leave, receipt of a disability pension, marital status, and number of children for each year starting 10 years before the date of study inclusion, birth, immigration, or start-up date of the registry recording the outcome of interest, up until the earliest of the following events: 10 years after study inclusion, 1 March 2016, death, emigration, or loss to follow-up. We calculated differences in each outcome between the patient and comparison cohorts, with 95\% confidence intervals. For children, we ascertained the grade received in written mathematics during the last year of primary school. We calculated time from age 17 to high school graduation and used Kaplan-Meier tables to calculate cumulative incidences of high school graduation at age 25. Analyses of income, sick leave, receipt of a disability pension, and number of children were restricted to people aged 20-60 years at study inclusion. Analyses of sick leave included only people registered as employed. To account for potential differences in comorbidity at time of study inclusion, we calculated the fraction of people with a Charlson 
Comorbidity Index score greater than 0 at study inclusion. ${ }^{17} 18$ We did similar calculations comparing family members of Lyme neuroborreliosis patients with family members of people in the population comparison cohort. We used SPSS Statistics version 24 and STATA version 14 for the analyses.

\section{Patient involvement}

No patients were involved in setting the research question or the outcome measures, nor were they involved in developing plans for design or implementation of the study. No patients were asked to advise on interpretation or writing up of results. There are no plans to disseminate the results of the research to study participants or the relevant patient community.

\section{Results}

During the study period, we identified 3200 people with a positive $B$ burgdorferi intrathecal test (supplementary figure A). Of these, 1047 (33\%) did not have a diagnosis of borreliosis recorded in the DNPR and $86(3 \%)$ were registered as having had contact with a department of neurology more than one year before study inclusion. After these exclusions, 2067 patients and 20670 members of the population comparison cohort remained in the study. Patients and members of the comparison cohort were well matched with respect to Charlson Comorbidity Index score and risk of cancer before study inclusion (table 1). We identified 3793 family members of people in the patient cohort and 37579 family members of people in the population comparison cohort (table 1).

A total of 247 (12\%) Lyme neuroborreliosis patients and 2728 (13\%) people in the population comparison cohort died during the observation period (table 1). Mortality was not higher among patients in the Lyme neuroborreliosis cohort (mortality rate ratio 0.90 ,
$95 \%$ confidence interval 0.79 to 1.03 ) or their family members (0.93, 0.81 to 1.07$)$ compared with people in the population comparison cohort and their family members (table 2, fig 1, supplementary figure B). Fifty nine patients were registered as having borreliosis in the DNPR more than one month after study inclusion, which may have introduced immortal time bias. The mortality estimate was not changed when we calculated time starting from study inclusion versus date of registration in the DNPR, whichever was later (mortality rate ratio $0.90,0.79$ to 1.03 ).

The risk of a new cancer was higher in the Lyme neuroborreliosis cohort than in the population comparison cohort(table 2). Theincreased riskstemmed mainly from a threefold higher risk of haematological cancer among Lyme neuroborreliosis patients; 29 patients and 94 comparison cohort members were diagnosed as having haematological cancer (table 2, fig 2). The Lyme neuroborreliosis population had increased risks of lymphoma, myelomatosis, and chronic lymphatic leukaemia (table 2). Mortality after a diagnosis of haematological cancer did not differ substantially between the patients and the population comparison cohort (mortality rate ratio 1.05, 0.65 to 1.69) (supplementary figure $C$ ). The increased risk of haematological cancer was evident throughout the study period and was also observed in a sensitivity analysis excluding patients who had a contact with a department of haematology before and up to one year after study inclusion (incidence rate ratio 2.84, 95\% confidence interval 1.81 to 4.47). In addition, the risk of non-melanoma skin cancers was almost 50\% higher in the patient cohort than in the population comparison cohort. Risks of haematological cancers and non-melanoma skin cancers were not increased among family members of Lyme neuroborreliosis patients (table 2, supplementary figure B).

\begin{tabular}{|c|c|c|c|c|}
\hline Characteristics & $\begin{array}{l}\text { LNB patients } \\
(n=2067)\end{array}$ & $\begin{array}{l}\text { Population comparison } \\
\text { cohort }(n=20670)\end{array}$ & $\begin{array}{l}\text { Family members of LNB } \\
\text { patients }(n=3793)\end{array}$ & $\begin{array}{l}\text { Family members of population } \\
\text { comparison cohort }(n=37579)\end{array}$ \\
\hline Female sex & $1160(56)$ & $11600(56)$ & $1881(50)$ & $18900(50)$ \\
\hline Median (interquartile range) age at study inclusion, years & $45(11-62)$ & $45(11-62)$ & $37(17-47)$ & $37(18-47)$ \\
\hline Age $<16$ years at study inclusion & $644(31)$ & $6440(31)$ & $2264(60)$ & $22458(60)$ \\
\hline Born in Denmark & $2012(97)$ & $19385(94)$ & 3739 (99) & $36045(96)$ \\
\hline Charlson Comorbidity Index score > $0^{\star} \dagger$ & $272(13)$ & $3135(15)$ & $426(11)$ & $4199(11)$ \\
\hline Cancer, totalt & $99(4.8)$ & $910(4.4)$ & $67(1.8)$ & $818(2.2)$ \\
\hline Non-melanoma-skin cancert & $37(1.8)$ & $318(1.5)$ & $4(0.1)$ & $93(0.2)$ \\
\hline Haematological cancert & $10(0.5)$ & $36(0.2)$ & $1(0.03)$ & $36(0.1)$ \\
\hline Other cancerst & $52(2.5)$ & $556(2.7)$ & $62(1.6)$ & $689(1.8)$ \\
\hline Fathers & - & - & $920(24)$ & $8822(24)$ \\
\hline Mothers & - & - & $999(26)$ & $9662(26)$ \\
\hline Siblings & - & - & $1874(49)$ & $19095(51)$ \\
\hline Median (interquartile range) observation time, years & $11.4(6.1-16.3)$ & $11.4(6.3-16.2)$ & $11.6(6.3-16.5)$ & $11.6(6.4-16.5)$ \\
\hline Total observation time, years & 23551 & 233740 & 44100 & 432625 \\
\hline Died $\neq$ & $247(12)$ & $2728(13)$ & $215(5.7)$ & $2278(6.1)$ \\
\hline Emigrated $\neq$ & $74(3.6)$ & $340(1.6)$ & $36(0.9)$ & $601(1.6)$ \\
\hline Lost to follow-up $\ddagger$ & 0 & $11(0.05)$ & 0 & $16(0.04)$ \\
\hline
\end{tabular}




\begin{tabular}{|c|c|c|}
\hline & $\begin{array}{l}\text { LNB patients v population } \\
\text { comparison cohort members }\end{array}$ & $\begin{array}{l}\text { Family members of LNB patients } v \text { family } \\
\text { members of population comparison cohort }\end{array}$ \\
\hline Mortality & $0.90(0.79$ to 1.03$)$ & $0.93(0.81$ to 1.07$)$ \\
\hline Cancer & $1.32(1.15$ to 1.52$)$ & $1.06(0.92$ to 1.22$)$ \\
\hline Non-haematological cancer & $1.19(1.00$ to 1.14$)$ & 1.12 (0.94 to 1.32$)$ \\
\hline Haematological cancer & $3.07(2.03$ to 4.66$)$ & 0.25 (0.08 to 0.77$)$ \\
\hline Lymphoma & $4.10(2.20$ to 7.64$)$ & - \\
\hline Myelomatosis & 2.62 (0.98 to 7.019$)$ & - \\
\hline Leukaemia (not chronic lymphatic leukaemia) & $1.36(0.41$ to 4.54$)$ & - \\
\hline Chronic lymphatic leukaemia & 3.67 (1.54 to 8.72$)$ & - \\
\hline Non-melanoma skin cancer & $1.49(1.18$ to 1.88$)$ & 1.11 (0.94 to 1.32$)$ \\
\hline Multiple sclerosis & 1.24 (0.37 to 4.12$)$ & $1.14(0.52$ to 2.49$)$ \\
\hline Arthritis $<1$ year after study inclusion ${ }^{\star}$ & $9.04(3.67$ to 22.24$)$ & $1.30(0.80$ to 2.10$)$ \\
\hline Arthritis $\geq 1$ year after study inclusion & $1.58(0.88$ to 2.84$)$ & - \\
\hline Skin diseases & $0.88(0.41$ to 1.91$)$ & $0.67(0.37$ to 1.21$)$ \\
\hline Cerebral infarction <1 year after study inclusion* & $4.85(2.92$ to 8.05$)$ & 0.99 (0.77 to 1.28$)$ \\
\hline Cerebral infarction $\geq 1$ year after study inclusion & $1.18(0.93$ to 1.50$)$ & - \\
\hline Heart block or cardiac arrest & $1.00(0.54$ to 1.87$)$ & 0.98 (0.53 to 1.83$)$ \\
\hline
\end{tabular}

We observed no increased risk of multiple sclerosis, skin diseases, heart block, or cardiac arrest in the Lyme neuroborreliosis patients (table 2, supplementary figure C). Risks of arthritis and cerebral infarction were increased among Lyme neuroborreliosis patients only during the first year after study inclusion (table 2).

Days of hospital admission and use of outpatient services were considerably higher in the patient cohort than in the general population comparison cohort during the year of Lyme neuroborreliosis diagnosis and then attenuated. Use of outpatient services remained slightly increased among Lyme neuroborreliosis patients for several years after diagnosis, particularly for services in haematology and neurology clinics (table 3, supplementary figure C). We observed no increased use of inpatient or outpatient hospital services in the family member cohort during the study period (table 3, supplementary figure D).

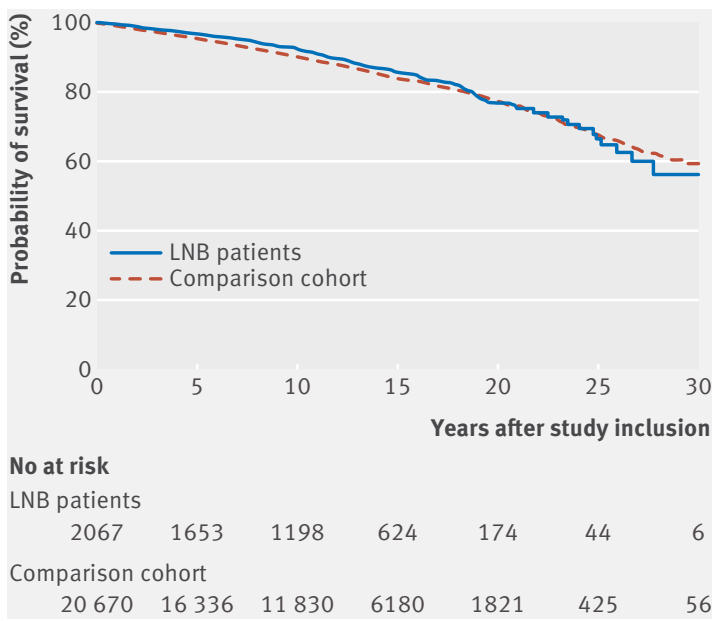

Fig 1 | Cumulative survival of 2067 Lyme neuroborreliosis (LNB) patients and 20670 members of population comparison cohort
The employment rate for people in the Lyme neuroborreliosis cohort was higher than in the population comparison cohort, although the rate in the patient cohort decreased slightly after study inclusion (table 3, supplementary figure E). Before study inclusion, the rate of receipt of disability pensions was lower among Lyme neuroborreliosis patients than among members of the population comparison cohort (table 3). Although the rate of receipt of disability pensions among patients increased after the date of study inclusion, it did not exceed the rate in the population comparison cohort (table 3, fig 3 (top)). We also observed a higher employment rate and a lower rate of receipt of disability pension among family members of Lyme neuroborreliosis patients, compared with family members of people in the general population comparison cohort (table 3, fig 3 (bottom), supplementary figure E).

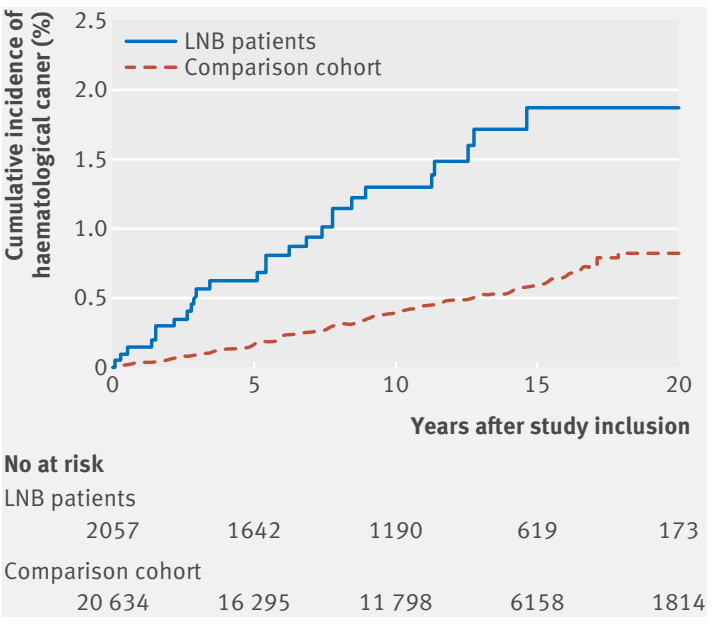

Fig 2 | Cumulative incidence of haematological cancer among Lyme neuroborreliosis (LNB) patients and members of population comparison cohort 


\begin{tabular}{|c|c|c|c|c|c|c|}
\hline Years from study inclusion & LNB patients & $\begin{array}{l}\text { Population } \\
\text { comparison } \\
\text { cohort }\end{array}$ & Difference $(95 \% \mathrm{Cl})$ & $\begin{array}{l}\text { Family members } \\
\text { of LNB patients }\end{array}$ & $\begin{array}{l}\text { Family members } \\
\text { of population } \\
\text { comparison cohort }\end{array}$ & Difference $(95 \% \mathrm{Cl})$ \\
\hline \multicolumn{7}{|l|}{ Hospital admission (mean inpatient days/year) } \\
\hline-2 & 0.71 & 0.54 & $0.17(-0.31$ to 0.66$)$ & 0.61 & 0.69 & $-0.09(-0.23$ to 0.06$)$ \\
\hline 0 & 14.21 & 0.76 & 13.45 (12.78 to 14.12$)$ & 0.88 & 0.80 & $0.07(-0.12$ to 0.27$)$ \\
\hline 1 & 0.98 & 0.95 & $0.03(-0.22$ to 0.29$)$ & 0.95 & 0.82 & $0.13(-0.11$ to 0.36$)$ \\
\hline 5 & 0.68 & 0.90 & $-0.22(-0.45$ to 0.02$)$ & 0.99 & 0.81 & $0.17(-0.23$ to 0.57$)$ \\
\hline 10 & 1.31 & 0.95 & $0.36(-0.17$ to 0.89$)$ & 0.87 & 0.82 & $0.06(-0.25$ to 0.37$)$ \\
\hline \multicolumn{7}{|l|}{ Outpatient visits (mean visits/year) } \\
\hline-2 & 0.80 & 0.87 & $-0.08(-0.25$ to 0.10$)$ & 0.81 & 0.85 & $-0.04(-0.12$ to 0.05$)$ \\
\hline 0 & 4.61 & 1.07 & $3.54(3.13$ to 3.95$)$ & 1.02 & 0.98 & $0.04(-0.08$ to 0.15$)$ \\
\hline 1 & 1.72 & 1.12 & $0.60(0.03$ to 0.90$)$ & 1.10 & 1.03 & $0.07(-0.05$ to 0.19$)$ \\
\hline 5 & 1.72 & 1.35 & $0.37(-0.10$ to 0.83$)$ & 1.17 & 1.20 & $-0.03(-0.15$ to 0.10$)$ \\
\hline 10 & 1.71 & 1.64 & $0.07(-0.40$ to 0.54$)$ & 1.58 & 1.51 & $0.07(-0.13$ to 0.27$)$ \\
\hline \multicolumn{7}{|l|}{ Proportion employed (\%)* } \\
\hline-2 & 90 & 86 & $3.9(1.7$ to 6.1$)$ & 91 & 88 & $2.7(1.4$ to 4.0$)$ \\
\hline 0 & 86 & 82 & $3.6(1.1$ to 6.2$)$ & 86 & 83 & 2.9 (1.4 to 4.4$)$ \\
\hline 1 & 81 & 80 & $0.8(-2.1$ to 3.6$)$ & 84 & 80 & $3.7(2.1$ to 0.3$)$ \\
\hline 5 & 70 & 69 & $1.5(-2.1$ to 5.1$)$ & 79 & 76 & $3.7(1.8$ to 5.7$)$ \\
\hline 10 & 51 & 51 & $0.3(-4.8$ to 4.3$)$ & 65 & 63 & $2.3(-0.3$ to 4.9$)$ \\
\hline \multicolumn{7}{|l|}{ Mean yearly income (Danish Kroner, thousands) ${ }^{\star}$} \\
\hline-2 & 262 & 245 & 17 (6 to 28$)$ & 277 & 261 & $16(7$ to 25$)$ \\
\hline 0 & 250 & 248 & $2(-10$ to 15$)$ & 290 & 262 & $27(2$ to 53$)$ \\
\hline 1 & 253 & 252 & $1(-14$ to 16$)$ & 284 & 264 & 20 (7 to 33$)$ \\
\hline 5 & 259 & 260 & $-1(-20$ to 18$)$ & 297 & 286 & $11(-2$ to 23$)$ \\
\hline 10 & 230 & 281 & $-51(-120$ to 19$)$ & 277 & 271 & 5 (-9 to 20$)$ \\
\hline \multicolumn{7}{|l|}{ Days of sick leave/yeart } \\
\hline-2 & 8.3 & 9.2 & $-0.9(-3.9$ to 2.1$)$ & 9.9 & 10.2 & $-0.3(-3.0$ to 2.3$)$ \\
\hline 0 & 45.5 & 10.1 & $35.5(29.7$ to 41.2$)$ & 9.9 & 9.5 & $0.4(-2.2$ to 2.9$)$ \\
\hline 1 & 24.5 & 9.4 & 15.1 (9.7 to 20.5) & 9.7 & 9.3 & $0.4(-2.3$ to 3.0$)$ \\
\hline 5 & 9.3 & 9.6 & $-0.3(-3.5$ to 3.0$)$ & 10.2 & 9.3 & $0.8(-2.1$ to 3.8$)$ \\
\hline 10 & 3.8 & 8.2 & $-4.4(-6.6$ to -2.2$)$ & 6.6 & 7.5 & $-0.9(-4.1$ to 2.4$)$ \\
\hline \multicolumn{7}{|l|}{ Proportion on disability pension (\%)* } \\
\hline-2 & 3.6 & 5.7 & $-2.2(-3.6$ to -0.8$)$ & 2.5 & 3.2 & $-0.7(-1.4$ to -0.1$)$ \\
\hline 0 & 4.8 & 6.5 & $-1.7(-3.3$ to -0.1$)$ & 3.0 & 3.9 & $-1.0(-1.7$ to -0.2$)$ \\
\hline 1 & 5.9 & 7.0 & $-1.1(-2.9$ to 0.7$)$ & 3.2 & 4.3 & $-1.0(-1.8$ to -0.2$)$ \\
\hline 5 & 8.3 & 9.2 & $-0.9(-3.2$ to 1.3$)$ & 4.3 & 5.7 & $-1.4(-2.4$ to -0.3$)$ \\
\hline 10 & 9.9 & 8.6 & $1.2(-1.7$ to 4.2$)$ & 4.8 & 7.0 & $-2.2(-3.5$ to -0.8$)$ \\
\hline \multicolumn{7}{|l|}{ Proportion married (\%)‡ } \\
\hline-2 & 72.0 & 68.9 & 3.1 (0.6 to 5.6$)$ & 68.3 & 65.8 & $2.5(0.6$ to 4.3$)$ \\
\hline 0 & 73.1 & 70.2 & $2.9(0.4$ to 5.3$)$ & 70.7 & 67.5 & $3.3(1.5$ to 5.1$)$ \\
\hline 1 & 74.0 & 70.6 & $3.4(0.9$ to 5.8$)$ & 71.0 & 68.2 & 2.7 (0.9 to 4.6) \\
\hline 5 & 77.0 & 72.2 & $4.8(2.2$ to 7.4$)$ & 72.6 & 69.8 & $2.8(0.8$ to 4.8$)$ \\
\hline 10 & 79.7 & 73.1 & $6.5(3.5$ to 9.5$)$ & 73.2 & 70.6 & $2.6(0.3$ to 4.9$)$ \\
\hline \multicolumn{7}{|l|}{ Proportion divorced (\%)‡ } \\
\hline-2 & 9.6 & 10.9 & $-1.3(-2.9$ to 0.4$)$ & 6.9 & 8.4 & $-1.5(-2.5$ to -0.5$)$ \\
\hline 0 & 9.9 & 11.4 & $-1.5(-3.1$ to 0.2$)$ & 7.8 & 9.6 & $-1.8(-2.9$ to -0.8$)$ \\
\hline 1 & 10.1 & 11.6 & $-1.6(-3.3$ to 0.1$)$ & 8.6 & 10.1 & $-1.5(-2.6$ to -0.3$)$ \\
\hline 5 & 9.8 & 12.0 & $-2.2(-4.1$ to -0.4$)$ & 9.9 & 12.3 & $-2.4(-3.7$ to -1.1$)$ \\
\hline 10 & 9.8 & 13.1 & $-3.3(-5.6$ to -1.1$)$ & 13.1 & 14.9 & $-1.8(-3.5$ to 0.0$)$ \\
\hline \multicolumn{7}{|l|}{ Number of children* } \\
\hline-2 & 1.00 & 1.00 & $-0.01(-0.16$ to 0.15$)$ & 1.81 & 1.71 & $0.10(0.03$ to 0.18$)$ \\
\hline 0 & 1.11 & 1.16 & $-0.05(-0.20$ to 0.10$)$ & 1.95 & 1.84 & 0.11 (0.03 to 0.19) \\
\hline 1 & 1.17 & 1.24 & $-0.07(-0.22$ to 0.08$)$ & 2.01 & 1.91 & $0.10(0.02$ to 0.18$)$ \\
\hline 5 & 1.41 & 1.50 & $-0.10(-0.27$ to 0.08$)$ & 2.18 & 2.14 & $0.03(-0.05$ to 0.12$)$ \\
\hline 10 & 1.72 & 1.72 & $0.00(-0.19$ to 0.19$)$ & 2.30 & 2.29 & $0.01(-0.09$ to 0.11$)$ \\
\hline \multicolumn{7}{|l|}{ Education } \\
\hline $\begin{array}{l}\text { High grade ( }>8) \text { in written mathematics in elementa- } \\
\text { ry school after diagnosis of LNB (\%)§ }\end{array}$ & 52 & 45 & $6(1$ to 12$)$ & 43 & 42 & $2(-3$ to 6$)$ \\
\hline Cumulative incidence of high school completion & 45 & 38 & 7 (1 to 12$)$ & 42 & 37 & 5 (1 to 10$)$ \\
\hline
\end{tabular}

before age 25 years (\%)

*Includes only people aged 20-60 years at study inclusion.

tIncludes only people aged 20-60 years at study inclusion and registered as employed.

fIncludes only people aged $>20$ years at study inclusion.

§Includes only siblings of LNB patients and population comparison cohorts.

IIncludes only people aged $<17$ years at study inclusion. 


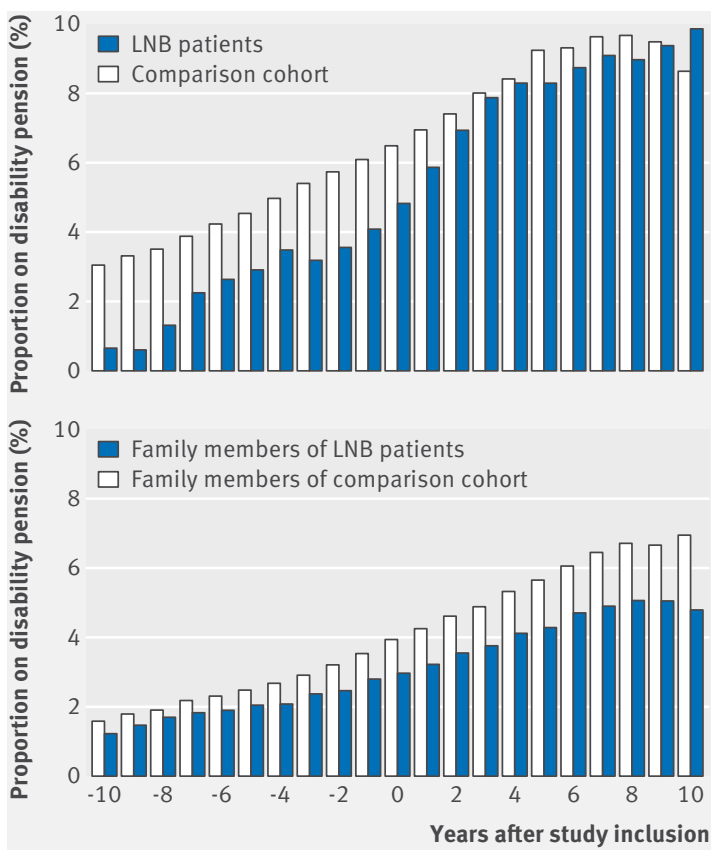

Fig 3 | Proportion of people aged 20-60 years at study inclusion registered as receiving disability pension. Top: Lyme neuroborreliosis (LNB) patients and members of population comparison cohort. Bottom: family members of LNB patients and family members of population comparison cohort

Before study inclusion, income was higher among Lyme neuroborreliosis patients than among members of the general population cohort, but it decreased thereafter (table 3, supplementary figure E). In contrast, the income of family members of Lyme neuroborreliosis patients was higher than that of family members of people in the comparison cohort throughout the observation period (table 3, supplementary figure E). Among Lyme neuroborreliosis patients, the number of days of sick leave was substantially higher than for members of the comparison cohort during the year of diagnosis. However, two years after diagnosis, the number of days of sick leave did not differ substantially from that for members of the comparison cohort (table 3, supplementary figure E).

Compared with the population comparison cohort, the marriage rate was increased and the divorce rate decreased among Lyme neuroborreliosis patients, before as well as after study inclusion. We observed a similar trend among family members of patients (table 3, supplementary figure F). The number of children was almost identical for Lyme neuroborreliosis patients and members of the population comparison cohort, as well as for the two cohorts of family members (table 3, supplementary figure F). Children diagnosed as having Lyme neuroborreliosis had higher marks in written mathematics in elementary school, and more Lyme neuroborreliosis patients completed high school, compared with members of the comparison cohort (table 3, fig 4).
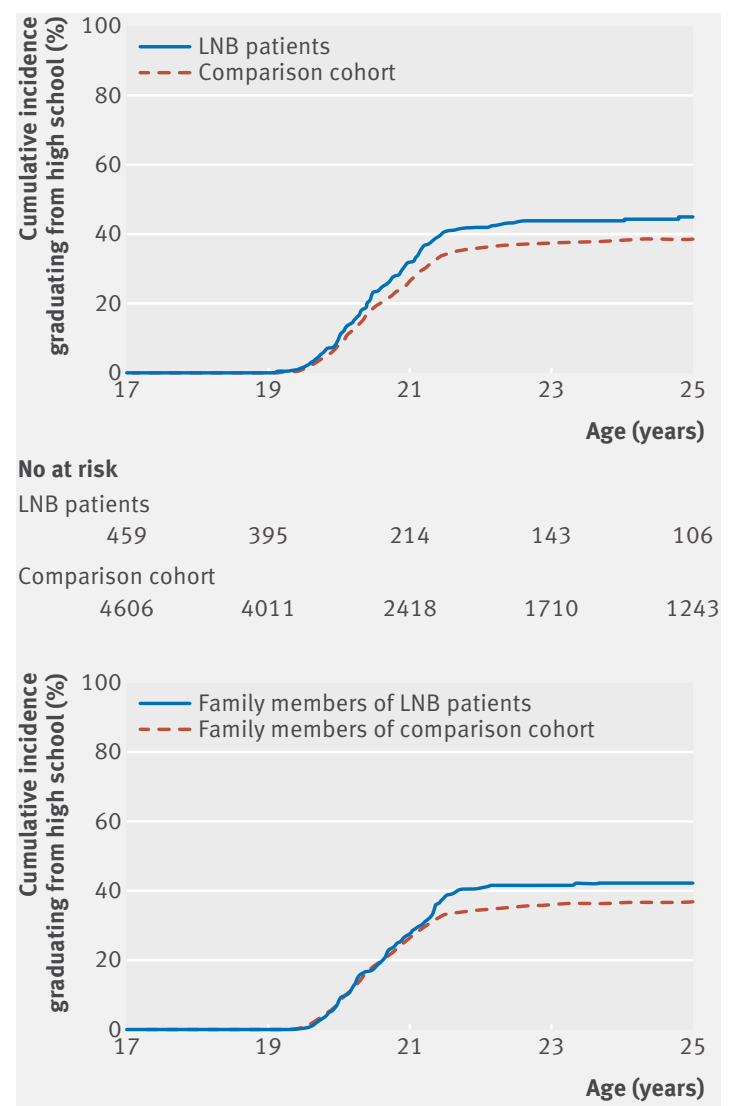

No at risk

Family members of LNB patients

$$
640
$$

560

328

218

168

Family members of comparison cohort 6302

$$
5530
$$

$$
3430
$$$$
2426
$$

Fig 4 | Cumulative incidence of people aged $<17$ years at study inclusion graduating from high school. Top: Lyme neuroborreliosis (LNB) patients and members of population comparison cohort. Bottom: family members of LNB patients and family members of population comparison cohort

\section{Discussion}

We did a population based nationwide cohort study of patients with Lyme neuroborreliosis among whom the diagnosis was established by a positive $B$ burgdorferi intrathecal antibody test and a clinical diagnosis of Lyme borreliosis. Compared with members of a general population cohort, mortality was not increased among Lyme neuroborreliosis patients. However, Lyme neuroborreliosis patients had an increased risk of haematological and nonmelanoma skin cancers. Before their diagnosis, Lyme neuroborreliosis patients, as well as their family members, had higher incomes and employment rates and were less likely to receive disability pensions than people in the comparison cohort and their family members. However, after diagnosis of Lyme neuroborreliosis, income and employment rates decreased and risk of receipt of disability pensions increased slightly in the patient population but not in their family members, relative to people in the comparison cohorts. 


\section{Strengths and limitations of study}

Important design features of this study are its large size, population based nationwide design, and complete long term follow-up of the study cohorts. Access to national registries allowed identification of a well matched population based comparison cohort and cohorts of family members. These registries provided complete data on date of death, comorbidity, cancer diagnoses, educational status, income, and disability pension status.

We included only patients with a first time proven positive $B$ burgdorferi intrathecal antibody test, which has a high diagnostic specificity for Lyme neuroborreliosis. ${ }^{16}$ Furthermore, the number of patients identified was in the same range as annual surveillance reports of Lyme neuroborreliosis. ${ }^{2}$ The registry based design precluded access to data on cerebrospinal fluid leucocyte counts and stage of Lyme neuroborreliosis, character of initial neurological symptoms, and antibiotic therapy. Therefore, we were unable to analyse the effect of clinical risk factors on long term prognosis. However, on the basis of the incidence reported in a previous Danish study, it is reasonable to assume that only a minority of patients had late disseminated (chronic or stage III) Lyme neuroborreliosis and that antibiotics were administered according to European treatment guidelines for this condition throughout the study period. ${ }^{319}$ By including only patients with a positive $B$ burgdorferi intrathecal test, we are likely to have missed some patients with early Lyme neuroborreliosis.

Long term prognosis of patients with post-treatment Lyme disease syndrome has been intensively debated. 561220 We must emphasise that our study focuses on patients with Lyme neuroborreliosis and was not designed to evaluate the prevalence of posttreatment Lyme disease syndrome.

\section{Comparison with other studies}

A key finding was the increased risk of haematological cancers up to 10 years after the Lyme neuroborreliosis diagnosis. A previous Danish-Swedish case-control study reported a threefold increased risk of mantle cell lymphoma in patients with a self reported history of Lyme borreliosis or presence of anti- $B$ burgdorferi antibodies. ${ }^{21}$ In contrast, a large registry based Swedish study observed no increased risk of haematological malignancies among patients with serological evidence of borreliosis. ${ }^{22}$ We found that mortality after a diagnosis of haematological cancer did not differ substantially between Lyme neuroborreliosis patients and people in the population comparison cohort; that the increased risk of haematological cancers persisted even after exclusion of patients who were treated at a hospital department of haematology up to one year after study inclusion; and that Lyme neuroborreliosis patients had increased use of haematological outpatient facilities. This indicates that the increased risk of haematological cancers is unlikely to be explained by the presence of clinically manifest haematological diseases before Lyme neuroborreliosis or by misclassification of the haematological disease. Our data do not allow firm conclusions concerning a causal link between risk of haematological cancers and Lyme neuroborreliosis. Patients had a slightly increased risk of being diagnosed as having haematological cancers before their Lyme neuroborreliosis diagnosis (table 1). Therefore, we may hypothesise that some Lyme neuroborreliosis patients harbour an unrecognised haematological malignancy or premalignant condition making them prone to second stage manifestations of Lyme borreliosis. In line with this hypothesis, invasive pneumococcal infection is associated with increased risk of a later diagnosis of myelomatosis. ${ }^{23}$ In addition, monoclonal B cell lymphocytosis increases the risk of infection and subsequent diagnosis of chronic lymphatic leukaemia. ${ }^{24}$ It remains possible that patients with an as yet unrecognised haematological cancer may have a higher risk of lumbar puncture and an intrathecal test for $B$ burgdorferi antibodies leading to a higher rate of Lyme neuroborreliosis diagnosis in this patient group.

Outdoor activities increase exposure to both ticks and to ultraviolet light. This probably explains the finding of a 50\% increased risk of non-melanoma skin cancers in Lyme neuroborreliosis patients. ${ }^{25}$

The increased risk of cerebral infarction during the first year after a Lyme neuroborreliosis episode is probably related to an increased frequency of neuroimaging procedures leading to detection of otherwise non-symptomatic cerebral infarctions. It is also consistent with reports of meningovascular involvement leading to lacunar infarctions secondary to obliteration of small penetrating arteries, primarily in patients with chronic Lyme neuroborreliosis. ${ }^{26}$

Lyme neuroborreliosis has been proposed to increase the risk of subsequent multiple sclerosis. ${ }^{27}$ However, we found no increased risk of this disease, consistent with a report on the geographical distribution of borreliosis and death due to multiple sclerosis in the United States. $^{28}$

Increased morbidity is assumed to lead to increased use of hospital services. We observed a slightly increased use of outpatient hospital services in Lyme neuroborreliosis patients even several years after their diagnosis, without a corresponding increased use of these services by their family members. This seemed to be partly due to residual symptoms of Lyme neuroborreliosis, as patients showed excess use of outpatient facilities treating neurological conditions. A US study based on insurance claims data reported that a diagnosis of Lyme borreliosis was associated with higher total healthcare costs and $87 \%$ more outpatient visits over a 12 month period compared with controls. $^{29}$

Lyme neuroborreliosis patients diagnosed in childhood and their siblings had higher educational achievement than members of the comparison cohort, indicating that Lyme neuroborreliosis in childhood does not affect cognition or learning ability and that the favourable educational outcome most likely stems from family related factors. 
Before the Lyme neuroborreliosis episode, patients and their family members had higher socioeconomic status compared with matched members of the general population cohort. However, after the Lyme neuroborreliosis diagnosis the employment rate and income among patients decreased to levels observed in the comparison cohort. At the same time, family members of Lyme neuroborreliosis patients maintained a higher level of income and employment than did family members of the comparison cohort. This indicates that Lyme neuroborreliosis decreases working capacity in a small fraction of patients, consistent with a Swedish study reporting a $12 \%$ rate of disabling sequelae five years after treatment for Lyme neuroborreliosis and with a Danish study that found a $5 \%$ rate of disability after a median 33 months of follow-up. ${ }^{39}$ Although living with a disabling chronic disease may increase the risk of divorce, we observed an increased marriage rate after the diagnosis of Lyme neuroborreliosis, compared with the general population cohort. ${ }^{3031}$

\section{Conclusion}

We conclude that a proven diagnosis of Lyme neuroborreliosis does not have a substantial effect on long term survival, health, social functioning, or education. However, a diagnosis of Lyme neuroborreliosis is associated with increased risk of haematological and non-melanoma skin cancers and marginally decreased labour marked attachment.

\section{AUTHOR AFFILIATIONS}

${ }^{1}$ Department of Infectious Diseases, Copenhagen University Hospital, Rigshospitalet, DK-2100, Copenhagen, Denmark

${ }^{2}$ Department of Clinical Microbiology, Slagelse Hospital, Slagelse, Denmark

${ }^{3}$ Bacteria, Parasites and Fungi Department, Statens Serum Institute, Copenhagen, Denmark

${ }^{4}$ Department of Clinical Microbiology and Infectious Diseases, Aalborg University hospital, Aalborg, Denmark

${ }^{5}$ Clinical Center for Emerging and Vector-borne Infections, Odense University Hospital, Odense, Denmark

${ }^{6}$ Department of Clinical Microbiology, Vejle Hospital, Vejle, Denmark

${ }^{7}$ Department of Clinical Microbiology, Copenhagen University Hospital, Rigshospitalet, Copenhagen, Denmark

${ }^{8}$ Department of Clinical Microbiology, Aarhus University Hospital, Aarhus, Denmark

${ }^{9}$ Department of Clinical Microbiology, Herlev University Hospital, Copenhagen, Denmark

${ }^{10}$ Department of Neurology, Copenhagen University Hospital, Rigshospitalet, Copenhagen, Denmark

${ }^{11}$ Department of Infectious Diseases, Hvidovre University Hospital, Copenhagen, Denmark

${ }^{12}$ Department of Clinical Epidemiology, Aarhus University Hospital, Aarhus, Denmark

${ }^{13}$ Department of Epidemiology, Boston University, Boston, MA, USA

${ }^{14}$ Department of Clinical Microbiology, Hvidovre University Hospital, Copenhagen, Denmark

We are grateful to Charlotte S Jørgensen, Virus and Microbiological Special Diagnostics, Statens Serum Institute, for help with extraction of data files on B burgdorferi intrathecal antibody tests.

Contributors: All authors contributed to the design, analysis, interpretation of data, drafting the article, or revising it critically for important intellectual content and approved the final version to be published. The corresponding author attests that all listed authors meet authorship criteria and that no others meeting the criteria have been omitted. NO and AML are the guarantors.

Funding: The study was sponsored by the Danish Council for Independent Research (grant number: 6110-00173B). HTS was supported by the PROCRIN program. The sponsors had no influence on the preparation, design, analysis, and reporting of this study.

Competing interests: All authors have completed the ICMJE uniform disclosure form at www.icmje.org/coi_disclosure.pdf (available on request from the corresponding author) and declare: no support from any organisation for the submitted work other than those listed above; $\mathrm{KH}$ has received royalties from Thermo Fisher; no other relationships or activities that could appear to have influenced the submitted work. Ethical approval: The study was approved by the Danish Data Protection Agency and the National Board of Health (RH-2015-285, I-Suite No: 04297).

Data sharing: Data are stored in Statistics Denmark and according to Danish data protection cannot be shared.

Transparency: The guarantors affirm that the manuscript is an honest, accurate, and transparent account of the study being reported; that no important aspects of the study have been omitted; and that any discrepancies from the study as planned (and, if relevant, registered) have been explained.

This is an Open Access article distributed in accordance with the Creative Commons Attribution Non Commercial (CC BY-NC 4.0) license, which permits others to distribute, remix, adapt, build upon this work non-commercially, and license their derivative works on different terms, provided the original work is properly cited and the use is non-commercial. See: http://creativecommons.org/licenses/ by-nc/4.0/.

1 Berglund J, Eitrem R, Ornstein K, et al. An epidemiologic study of Lyme disease in southern Sweden. N Engl J Med 1995;333:1319-27. doi:10.1056/NEJM199511163332004

2 Dessau RB, Espenhain L, Mølbak K, Krause TG, Voldstedlund M. Improving national surveillance of Lyme neuroborreliosis in Denmark through electronic reporting of specific antibody index testing from 2010 to 2012. Euro Surveill 2015;20:pii21184 doi:10.2807/1560-7917.ES2015.20.28.21184

3 Hansen K, Lebech AM. The clinical and epidemiological profile of Lyme neuroborreliosis in Denmark 1985-1990. A prospective study of 187 patients with Borrelia burgdorferi specific intrathecal antibody production. Brain 1992;115:399-423. doi:10.1093/ brain/115.2.399

4 Hansen K, Crone C, Kristoferitsch W. Lyme neuroborreliosis. In: Said G, Krarup C, eds. Handbook of clinical neurology. Elsevier, 2013: 559-75.

5 Stanek G, Wormser GP, Gray J, Strle F. Lyme borreliosis. Lancet 2012:379:461-73. doi:10.1016/S0140-6736(11)60103-7

6 Koedel U, Pfister HW. Lyme neuroborreliosis. Curr Opin Infect Dis 2017;30:101-7.

7 Christen HJ. Lyme neuroborreliosis in children. Ann Med 1996:28:235-40. doi:10.3109/07853899609033125

8 Krüger H, Reuss K, Pulz M, et al. Meningoradiculitis and encephalomyelitis due to Borrelia burgdorferi: a follow-up study of 72 patients over 27 years. J Neurol 1989;236:322-8. doi:10.1007/ BF00314373

9 Berglund J, Stjernberg L, Ornstein K, Tykesson-Joelsson K, Walter H. 5-y Follow-up study of patients with neuroborreliosis. Scand J Infect Dis 2002;34:421-5. doi:10.1080/00365540110080421

10 Ljøstad U, Mygland A. Remaining complaints 1 year after treatment for acute Lyme neuroborreliosis; frequency, pattern and risk factors. Eur J Neurol 2010;17:118-23. doi:10.1111/j.14681331.2009.02756.x

11 Eikeland R, Mygland A, Herlofson K, Ljøstad U. European neuroborreliosis: quality of life 30 months after treatment Acta Neurol Scand 2011;124:349-54. doi:10.1111/j.16000404.2010.01482.x

12 Dersch R, Sarnes AA, Maul M, et al. Quality of life, fatigue, depression and cognitive impairment in Lyme neuroborreliosis. J Neurol 2015;262:2572-7. doi:10.1007/s00415-015-7891-4

13 Eikeland R, Ljøstad U, Mygland A, Herlofson K, Løhaugen GC. European neuroborreliosis: neuropsychological findings 30 months post-treatment. Eur J Neurol 2012;19:480-7. doi:10.1111/j.14681331.2011.03563.x

14 Dersch R, Sommer H, Rauer S, Meerpohl JJ. Prevalence and spectrum of residual symptoms in Lyme neuroborreliosis after pharmacological treatment: a systematic review. J Neurol 2016;263:17-24. doi:10.1007/s00415-015-7923-0

15 Roed C, Omland LH, Skinhoj P, Rothman KJ, Sorensen HT, Obel N. Educational achievement and economic self-sufficiency in adults after childhood bacterial meningitis. JAMA 2013;309:1714-21. doi:10.1001/jama.2013.3792 
16 Hansen K, Lebech AM. Lyme neuroborreliosis: a new sensitive diagnostic assay for intrathecal synthesis of Borrelia burgdorferi-specific immunoglobulin G, A, and M. Ann Neurol 1991;30:197-205. doi:10.1002/ana.410300212

17 Charlson ME, Pompei P, Ales KL, MacKenzie CR. A new method of classifying prognostic comorbidity in longitudinal studies: development and validation. J Chronic Dis 1987;40:373-83. doi:10.1016/0021-9681(87)90171-8

18 Thygesen SK, Christiansen CF, Christensen S, Lash TL, Sørensen HT. The predictive value of ICD-10 diagnostic coding used to assess Charlson comorbidity index conditions in the populationbased Danish National Registry of Patients. BMC Med Res Methodol 2011;11:83. doi:10.1186/1471-2288-11-83

19 Mygland A, Ljøstad U, Fingerle V, Rupprecht T, Schmutzhard E, Steiner IEuropean Federation of Neurological Societies. EFNS guidelines on the diagnosis and management of European Lyme neuroborreliosis. Eur J Neurol 2010;17:8-16, e1-4. doi:10.1111/ j.1468-1331.2009.02862.x

20 Klempner MS, Hu LT, Evans J, et al. Two controlled trials of antibiotic treatment in patients with persistent symptoms and a history of Lyme disease. N Engl J Med 2001;345:85-92. doi:10.1056/ NEJM200107123450202

21 Schöllkopf C, Melbye M, Munksgaard L, et al. Borrelia infection and risk of non-Hodgkin lymphoma. Blood 2008;111:5524-9. doi:10.1182/blood-2007-08-109611

22 Chang CM, Landgren O, Koshiol J, Björkholm M, Löve T], Kristinsson SY. Borrelia and subsequent risk of solid tumors and hematologic malignancies in Sweden. Int J Cancer 2012;131:2208 9. doi:10.1002/ijc.27483

23 Roed C, Engsig FN, Omland LH, Skinhoj P, Obel N. Long-term mortality in patients diagnosed with pneumococcal meningitis: a Danish nationwide cohort study. Am J Epidemiol 2010;172:309-17. doi:10.1093/aje/kwq126
24 Moreira J, Rabe KG, Cerhan JR, et al. Infectious complications among individuals with clinical monoclonal B-cell lymphocytosis (MBL): a cohort study of newly diagnosed cases compared to controls. Leukemia 2013;27:136-41. doi:10.1038/leu.2012.187

25 Hall JL, Alpers K, Bown KJ, Martin SJ, Birtles RJ. Use of MassParticipation Outdoor Events to Assess Human Exposure to Tickborne Pathogens. Emerg Infect Dis 2017;23:463-7. doi:10.3201/ eid2303.161397

26 Garkowski A, Zajkowska J, Zajkowska A, et al. Cerebrovascular Manifestations of Lyme Neuroborreliosis-A Systematic Review of Published Cases. Front Neurol 2017;8:146. doi:10.3389/ fneur.2017.00146

27 Nicolson GL. Chronic Bacterial and Viral Infections in Neurodegenerative and Neurobehavioral Diseases. Lab Med 2008;39:291-9. doi:10.1309/96M3BWYP42L11BFU.

28 Forrester JD, Kugeler KJ, Perea AE, Pastula DM, Mead PS No Geographic Correlation between Lyme Disease and Death Due to 4 Neurodegenerative Disorders, United States, 20012010. Emerg Infect Dis 2015;21:2036-9. doi:10.3201/ eid2111.150778

29 Adrion ER, Aucott J, Lemke KW, Weiner JP. Health care costs, utilization and patterns of care following Lyme disease. PLOS One 2015;10:e0116767. doi:10.1371/journal.pone.0116767

30 Pfleger CCH, Flachs EM, Koch-Henriksen N. Social consequences of multiple sclerosis. Part 2. Divorce and separation: a historical prospective cohort study. Mult Scler 2010;16:878-82. doi:10.1177/1352458510370978

31 Meenan RF, Yelin EH, Nevitt M, Epstein WV. The impact of chronic disease: a sociomedical profile of rheumatoid arthritis. Arthritis Rheum 1981;24:544-9. doi:10.1002/art.1780240315

\section{Supplementary materials}

